\title{
Synthesis of a sulfated-group-riched carbonaceous catalyst and its application in the esterification of succinic acid and fructose dehydration to form HMF
}

\author{
Huihui Liu ${ }^{1} \cdot$ Qian Peng ${ }^{1} \cdot$ Jiawen Ren ${ }^{1} \cdot$ Bianfang Shi $^{2} \cdot$ Yanqin Wang ${ }^{1}$
}

Received: 18 May 2018 / Accepted: 16 February 2021 / Published online: 2 April 2021

(c) The Author(s) 2021

\begin{abstract}
A novel sulfated-group-riched sulfonated carbonaceous catalyst with high acidic strength and adjustable ratio of acidic groups was designed in the paper, where glucose and benzyl chloride were hydrothermally carbonized first followed by sulfonation treatment. Various physicochemical techniques were used to characterize the catalyst such as IR, 13C MAS NMR and XPS spectra, NH3-TPD, XRD patterns and TG curve. Then, it was applied in the esterification of succinic acid and fructose dehydration to form HMF. Compared to commercial Amberlyst-15 catalyst, such carbonaceous solid acid exhibited excellent catalytic activity and thermal stability, which was attributed to its higher amount of sulfonic acid group.
\end{abstract}

Keywords Hydrothermal carbonization · Heterogeneous catalysis · Etherification · Fructose dehydration

\section{Introduction}

The transformation of renewable resources into fuels and chemicals has aroused increasing attention since it can be an alternative to the exhausted fossil fuels [1-3]. Traditional homogeneous Brønsted acids such as $\mathrm{H}_{2} \mathrm{SO}_{4}$ and $\mathrm{H}_{3} \mathrm{PO}_{4}$ are essential catalysts in the reaction-related biomass conversion. However, such liquid acid catalysts require energyinefficient processing for separation and neutralization. Recently, much attention has focused on solid acid catalysts since they have advantages of environmental friendly, high stability and easy recyclability, such as transition metal oxide or phosphates, H-type molecular sieve [4-6], functionalized

Huihui Liu

liuhuihui@ecust.edu.cn

Bianfang Shi

shibf@ecust.edu.cn

1 Shanghai Key Laboratory of Functional Materials Chemistry, and Research Institute of Industrial Catalysis, School of Chemistry and Molecular Engineering, East China University of Science and Technology, Shanghai 200237, People's Republic of China

2985 Instrument Public Analysis Center, School of Chemical Engineering, East China University of Science and Technology, Shanghai 200237, People's Republic of China magnetic nanocomposite [7-10] so on. The use of carbonaceous materials as catalysts for various organic transformations has become increasingly attractive as metal-free alternatives to inorganic catalysts [11]. Sulfonated carbon is one type of a solid acid catalyst that has been well studied because of its easy preparation and tunable surface properties and has been reported to replace sulfuric acid in many reactions [12-21].

For example, Zhang's group reported the sulfonated CMK-3 showed good catalytic activity in the selective hydrolysis of cellulose to glucose [22]. The glucose yield could be up to $74.5 \%$, which is higher than that produced by molecular sieves. Sarma explored carbon dots decorated with hydrogen sulfate groups as a photocatalyst for the dehydrogenative cross-coupling of xanthenes with ketones, arenes and 1,3-dicarbonyl compounds that showed high efficiency and selectivity under visible-light irradiation [11]. Clark prepared a starch derivatives named "Starbon". The sulfonated carbonaceous materials were obtained and showed a significant catalytic activity in the esterification of succinic acid [14, 23]. Succinic acid is usually used to transform and generate various valuable products and can be obtained from glucose production. Obviously, sulfonated carbonaceous materials are also very suitable for catalytic conversion of biomass.

It is well known that the catalytic activity of the sulfonated carbonaceous materials strongly depends on the 
nature of the carbon materials $[24,25]$. At present, one of the most used methods to prepare the highly efficient carbonaceous solid acid materials is sulfonation of carbon materials with concentrated or fumed sulfuric acid. The carbon materials were obtained by treating carbohydrate or polycyclic aromatic hydrocarbons at high temperature $\left(400{ }^{\circ} \mathrm{C}\right.$ ) and inert atmosphere for long time (above $15 \mathrm{~h}$ ) $[15,26]$. According to previous reports, the carbonization temperature is a key parameter. Sulfonation of carbon materials, which were carbonized at high temperature $\left(750{ }^{\circ} \mathrm{C}\right)$, could obtain surface amorphous carbon rich in sulfonic groups, but the sulfonated carbonaceous materials showed no catalytic activity [27]. This means that the structure and properties of carbon materials are key to the preparation of efficient solid acids. Recently, much attention has been paid to the hydrothermal carbonization method (HTC) because of its maneuverability [28, 29], mild operation conditions (160-200 ${ }^{\circ} \mathrm{C}$ ) and low operation cost. More importantly, HTC is an environmentally friendly method and can be used to prepare carbon materials with controllable functional groups [30, 31].

In this work, we prepared sulfonated carbonaceous materials with high acidity and adjustable acid content with glucose and benzyl chloride. It is composed of two steps. Firstly, carbon materials rich in phenyl groups on the surface were prepared by treating with glucose and benzyl chloride in a certain mass ratio mixed at $180{ }^{\circ} \mathrm{C}$ for $24 \mathrm{~h}$, and then, the prepared carbon materials were sulfonated with concentrated sulfuric acids. The amount of sulfonic group can be controlled by changing the mass ratio of glucose to benzyl chloride. The sulfonated carbonaceous materials showed higher catalytic performance in esterification of succinic acid with ethanol and fructose dehydration, compared with sulfonated resin Amberlyst- 15 and the traditional H- $\beta$ molecular sieve catalysts. It is worth mentioning that other monosaccharides and polysaccharides and even cellulose can also be used as precursor materials and can be used for the controllable preparation of solid acid catalysts.

\section{Experiments}

\section{Chemical reagent}

Activated carbon with surface area of $1041 \mathrm{~m}^{2} \mathrm{~g}^{-1}$ (calculated by the Brunauer-Emmett-Teller (BET) method) and pore volume of $1.05 \mathrm{~mL} \mathrm{~g}^{-1}$ was purchased from Shanghai Tangxin Corporation. Glucose, benzyl chloride, succinic acid, concentrated sulfuric acid, ethanol and other regents were obtained from Shanghai Chemical Co. All chemicals were of A. R. grade and used as received without further purification.

\section{Synthesis of $\mathrm{SO}_{3} \mathrm{H}$-functionalized solid acid catalyst}

$\mathrm{SO}_{3} \mathrm{H}$-functionalized solid acid catalyst was synthesized via two steps; the detail procedure is as follows: $4 \mathrm{~g}$ of glucose and a certain amount of benzyl chloride were mixed together by grinding, and then, the mixture were transferred to a Teflon-lined stainless-steel autoclave $(25 \mathrm{~mL}$ capacity). After reaction at $180^{\circ} \mathrm{C}$ for $24 \mathrm{~h}$, the autoclave was cooled down to room temperature. The brown solid product (noted as SAC-4-X, X represents the amount of benzyl chloride) was washed several times with diluted water and ethanol and then dried in an oven overnight. Finally, $1 \mathrm{~g}$ of solid carbon was added into $5 \mathrm{~mL}$ concentrated sulfuric acid and reacted at $180{ }^{\circ} \mathrm{C}$ for $24 \mathrm{~h}$ mixed uniformly. After cooling, the solid product (noted as SAC4-X-SO $\mathrm{S}_{3} \mathrm{H}$ ) was carefully removed out from the container and washed with water/ethanol followed drying overnight. For comparison, the $\mathrm{AC}-\mathrm{SO}_{3} \mathrm{H}$ were also prepared. The precursor of this carbon is pine wood, and the activation agent is $\mathrm{H}_{3} \mathrm{PO}_{4}$.

\section{Characterization}

The powder X-ray diffraction patterns were collected in $\theta-2 \theta$ mode using a Bruker D8 Focus diffractometer (CuKa1 radiation, $k=1.5406 \AA$ ), operating at $40 \mathrm{kV}$ and $40 \mathrm{~mA}$ (scanning step: $0.02^{\circ}$ per step). Nitrogen sorption isotherms were measured at $77 \mathrm{~K}$ with a Micromeritics ASAP 2020 sorption analyzer. Before the measurements, the samples were degassed at $90{ }^{\circ} \mathrm{C}$ in vacuum for $6 \mathrm{~h}$. The BET method was utilized to calculate the specific surface areas. Fourier transform infrared spectroscopy (FT-IR) was carried out on a Nicolet Nexus 670 FT-IR spectrometer in the range of $400-4000 \mathrm{~cm}^{-1}$. The samples were ground along with $\mathrm{KBr}$ and then pressed into thin wafers for IR analysis. Thermal gravimetric analysis (TG) and differential thermal gravimetric analysis (DTA) of the as-synthesized samples were performed at a heating rate of $10{ }^{\circ} \mathrm{C} \mathrm{min}{ }^{-1}$ from 40 to $700{ }^{\circ} \mathrm{C}$ in flowing air by using WCT-2 thermal analyzer (PerkinElmer Pyris, Champaign, IL, USA). The sulfur element content was measured by energy-dispersive spectrometer (EDS) in the scanning electron microscope (SEM) (JSM-6360LV). $\mathrm{X}$-ray photoelectron spectroscopy (XPS) analysis was performed on a Thermo ESCA LAB-250 spectrometer, using monochromatic Al-K radiation source $(1486.6 \mathrm{eV}$, pass energy $20.0 \mathrm{eV}$ ). The temperature-programmed desorption of ammonia ( $\mathrm{NH}_{3}$-TPD) was used to measure the surface acidity. Solid-state 13C MAS NMR analysis was performed on a Bruker Avance $500 \mathrm{MHz}$ NMR 
spectrometers. Surface acid amount of samples (SAC-4$\mathrm{X}-\mathrm{SO}_{3} \mathrm{H}$ ) was measured through Boehm titration method [32] to determine the type and amounts of its surface acid radical groups.

\section{Catalytic performance}

\section{Succinic acid and ethanol esterification reaction}

$0.1 \mathrm{~g}$ catalyst (SAC-4-2- $\left.\mathrm{SO}_{3} \mathrm{H}\right), 1 \mathrm{mmol}$ succinic acid (SA, $0.118 \mathrm{~g}$ ) and $80 \mathrm{mmol}$ anhydrous ethanol (EtOH, $4.6 \mathrm{~mL}$ ) were added to a $25-\mathrm{mL}$ round-bottom flask; then, the reaction mixture was stirred magnetically and refluxed at $80^{\circ} \mathrm{C}$. After $4 \mathrm{~h}$, the reaction mixture was separated with centrifugal machine, and the supernatant fluid was analyzed by gas chromatography (GC). The conversion of succinic acid was calculated by normalization method. Product composition was determined by gas chromatography-mass spectrometry (GC-MS). Catalyst was collected by centrifuged separation and then washed with water and ethanol several times and then dried at $90{ }^{\circ} \mathrm{C}$ overnight. The dried catalyst was added into the fresh reactant with the same ratio, and then, the activity measurement was taken. The process was repeated several times, and the catalytic stability was obtained.

For comparison, the performance of other catalyst such as Amberlyst 15, $\mathrm{AC}-\mathrm{SO}_{3} \mathrm{H}, \mathrm{SAC}-4-0-\mathrm{SO}_{3} \mathrm{H}$ and $\mathrm{H}-\beta$ zeolite, as well as a blank control experiment, was also carried out under the same reaction conditions.

\section{Fructose dehydration to form HMF reaction}

$0.25 \mathrm{~g}$ of catalyst (SAC-4-2- $\left.\mathrm{SO}_{3} \mathrm{H}\right), 0.5 \mathrm{~g}$ of fructose, $8 \mathrm{ml}$ of acetone solvent (acetone), and $2 \mathrm{ml}$ of dimethyl sulfoxide (DMSO) were added in a 50-mL round-bottom flask, under nitrogen protection, and magnetic stirring at $130{ }^{\circ} \mathrm{C}$ for $1 \mathrm{~h}$ in oil bath. After the completion of the reaction, the product obtained after centrifugal supernatant fluid for high-performance liquid chromatography (HPLC) analysis. Fructose conversion rate and the yield of results were calculated by external standard method. Centrifugal catalyst was washed by water and ethanol several times after and then dried at $80{ }^{\circ} \mathrm{C}$ overnight. The dried catalyst was added into the fresh reactant by the same ratio.

Comparison experiment: under the same reaction conditions, we also evaluated the reactivities of other catalysts: Amberlyst-15, $\mathrm{AC}-\mathrm{SO}_{3} \mathrm{H}$, as well as a blank control experiment.

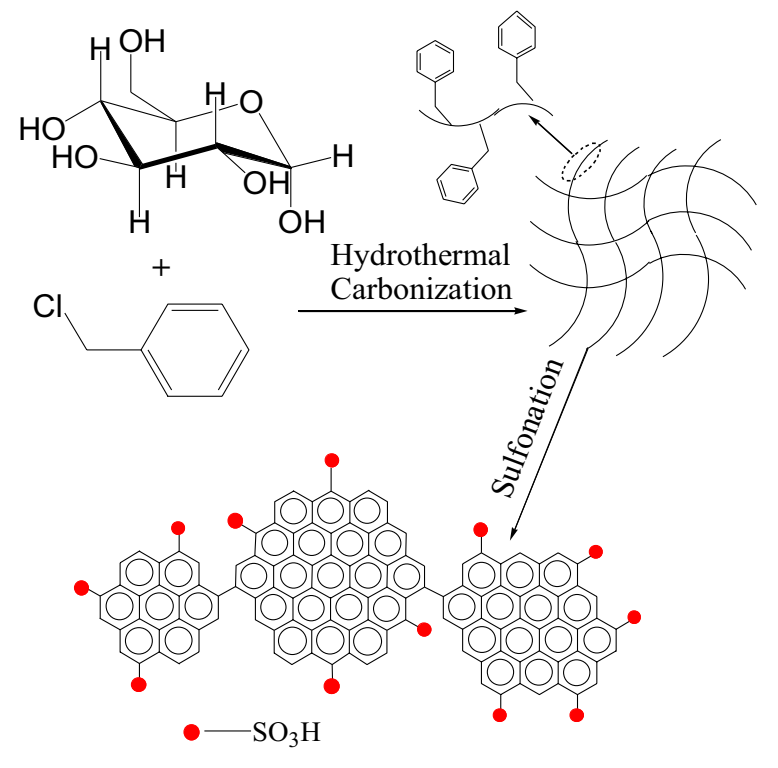

Scheme 1 The proposed synthetic route of the catalyst

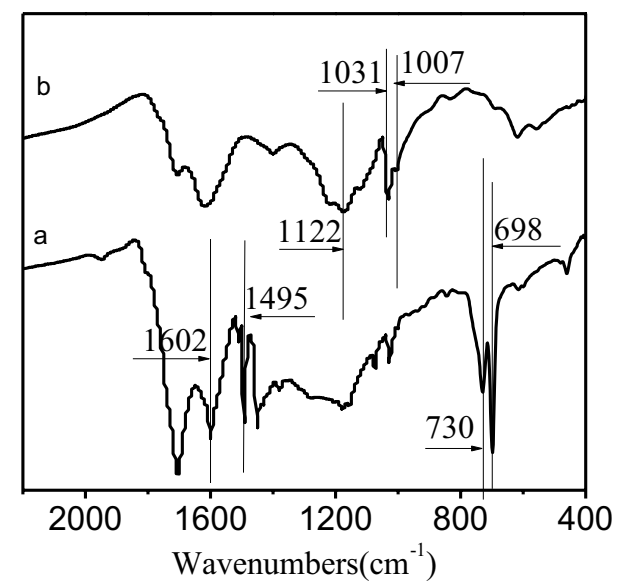

Fig. 1 The IR spectra of carbonaceous catalyst a SAC-4-2 and b SAC-4-2- $\mathrm{SO}_{3} \mathrm{H}$

\section{Results and discussions}

\section{Characterization}

Scheme 1 illustrates the preparation process and the possible mechanism of the materials. Firstly, the dehydration reaction occurred between the glucose and obtained hydrothermal carbon. At the same time, the Williamson esterification reaction happened between benzyl chloride and the surface hydroxyl of hydrothermal carbon and then produced the carbonaceous materials rich in phenyl groups. This can be determined by IR spectrum, as shown in Fig. 1a. The absorption peaks at 698 and $730 \mathrm{~cm}^{-1}$ can 
be attributed to the $\mathrm{C}-\mathrm{H}$ bending vibration of benzene ring, and peaks at 1495 and $1602 \mathrm{~cm}^{-1}$ are attributed to the $\mathrm{C}=\mathrm{C}$ stretching vibration of the benzene ring. The aromatic ring offers a wide range of active site for sulfonation. The solid acid catalyst rich in sulfonic groups can be obtained by sulfonating the carbon rich in phenyl groups with concentrated sulfuric acid.

Figure $1 \mathrm{~b}$ shows infrared spectrogram of SAC-4-2- $\mathrm{SO}_{3} \mathrm{H}$. Absorption peaks at 1007, 1031 and $1122 \mathrm{~cm}^{-1}$ belong to $-\mathrm{SO}_{3} \mathrm{H}$ [12], while those at 834 and $1602 \mathrm{~cm}^{-1}$ absorption peak position belong to the benzene ring. This suggests that $-\mathrm{SO}_{3} \mathrm{H}$ was assembled into the carbon skeleton.

Figure 2 shows the ${ }^{13} \mathrm{C}$ MAS NMR spectra of SAC-4-2 and SAC-4-2- $\mathrm{SO}_{3} \mathrm{H}$. The peak of $128 \mathrm{ppm}$ for the SAC-4-2 is attributed to $\mathrm{Ar}-\mathrm{C}=\mathrm{C}-\mathrm{Ar}$ [33], which indicates that during the first step of the synthesis process the carbon material successfully bonded to the benzene rings. The peaks at 25 to $50 \mathrm{ppm}$ belong to the unconsumed glucose. Peaks at 127 and $141 \mathrm{ppm}$ for SAC-4-2 and $-\mathrm{SO}_{3} \mathrm{H}$ indicate the existence of unsulfonated and sulfonated polycyclic aromatic hydrocarbons [26], consistent with the possible mechanism of the synthetic route.

XPS further demonstrates the existence of sulfonic group in the catalyst. As shown in Fig. 3, the strong S2p peak at $168.2 \mathrm{eV}$ belongs to $-\mathrm{SO}_{3} \mathrm{H}$ group [24]. This indicates that almost of $\mathrm{S}$ all in the samples exist in the form of $-\mathrm{SO}_{3} \mathrm{H}$. However, there is a weaker peak at $169.8 \mathrm{eV}$ (peak area no larger than 10\%), suggesting the existence of small amounts of $-\mathrm{O}-\mathrm{SO}_{3} \mathrm{H}$ [34].

The acid amounts in the sample are determined by the Boehm titration method with different reagents; sulfur content is measured by EDAX energy spectrum, as listed in Table 1. We can see that the sulfur content in the samples calculated by EDAX is higher than that obtained by the titration method. This shows that a small number of

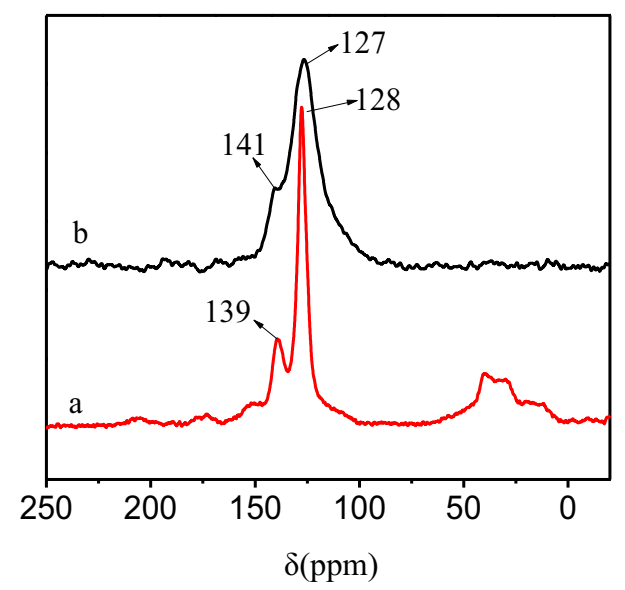

Fig. 2 The ${ }^{13} \mathrm{C}$ MAS NMR spectra of carbonaceous catalyst a SAC4-2 and b SAC-4-2- $\mathrm{SO}_{3} \mathrm{H}$ sulfonic groups in the sample are unable to be used, which may be embedded inside the sample. On the other hand, the sulfur and sulfonic group contents increased with the increase of adding amount of benzyl chloride. Especially for the sample SAC-4-0-SO $\mathrm{S}_{3} \mathrm{H}$ without adding benzyl chloride in the synthesis, it has extremely low content of sulfur $\left(0.38 \mathrm{mmol} \mathrm{g}^{-1}\right)$ and sulfonic group $\left(0.36 \mathrm{mmol} \mathrm{g}^{-1}\right)$. This suggests that the presence of aromatic ring is a key factor for the preparation of solid acid catalyst with high content of sulfonic groups. Sample SAC-4-2- $\mathrm{SO}_{3} \mathrm{H}$ has roughly the same amount of sulfonic group as $\mathrm{SAC}-4-3-\mathrm{SO}_{3} \mathrm{H}$, which suggests that the addition of $2 \mathrm{~g}$ of benzyl chloride was enough for the complete reaction with surface hydroxyls. In addition, it also means that the amount of sulfuric group can be adjusted by controlling the amount of added benzyl chloride. Because of the existence of other acidic groups such as carboxyl and hydroxyl groups, the total acid content from $\mathrm{NaOH}$ titration is higher than the total sulfonic acid content. Because different acidic groups possess different acid strengths, the acid distribution can be determined by Boehm titration, and the results are shown in Table 1. A work reported recently proposed that coexistence of various functional groups on the surface may be beneficial for some catalytic reactions [16].

$\mathrm{NH}_{3}$-TPD-MS further identified the acid strength of the sample [35]. As shown in Fig. 4, the $\mathrm{NH}_{3}$ desorption could happen in the high-temperature range of $600-750{ }^{\circ} \mathrm{C}$, suggesting the existence of strong acid site. Besides, the desorption peak for $\mathrm{NH}_{3}$ in $100-500{ }^{\circ} \mathrm{C}$ also showed that the catalyst is abundant in weak acid and medium strong acid, which is consistent with the result from titration.

Obviously, the initially added benzyl chloride contributes to the production of a large number of phenyl carbon materials on the surface. X-ray diffraction pattern of the catalyst is also slightly affected. As shown in Fig. 5, both SAC-4$0-\mathrm{SO}_{3} \mathrm{H}$ and $\mathrm{SAC}-4-2-\mathrm{SO}_{3} \mathrm{H}$ have a wide diffraction peak

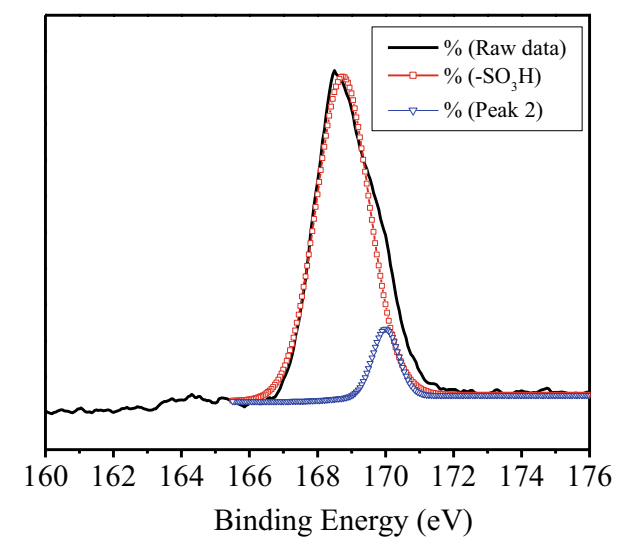

Fig. 3 The S2p XPS spectra of $\mathrm{SO}_{3} \mathrm{H}$-functionalized solid acid catalyst $\mathrm{SAC}-4-2-\mathrm{SO}_{3} \mathrm{H}$ 
Table 1 Surface areas and chemistry of different catalysts

\begin{tabular}{llllll}
\hline Catalysts & $\mathrm{S}_{\mathrm{BET}}\left(\mathrm{m}^{2} / \mathrm{g}\right)$ & $\begin{array}{l}\mathrm{S} \text { content } \\
(\mathrm{mmol} \mathrm{g})^{-1}\end{array}$ & $\begin{array}{l}\text { Total acid density } \\
\left(\mathrm{mmol} \mathrm{g}^{-1}\right)^{\mathrm{b}}\end{array}$ & $\begin{array}{l}-\mathrm{SO}_{3} \mathrm{H} \text { groups } \\
\left(\mathrm{mmol} \mathrm{g}^{-1}\right)^{\mathrm{c}}\end{array}$ & $\begin{array}{l}\text {-COOH } \\
\text { groups } \\
\left(\mathrm{mmol} \mathrm{g}^{-1}\right)^{\mathrm{d}}\end{array}$ \\
\hline $\mathrm{SAC}-4-0-\mathrm{SO}_{3} \mathrm{H}$ & 12 & 0.38 & 4.02 & 0.36 & 3.53 \\
$\mathrm{SAC}-4-1-\mathrm{SO}_{3} \mathrm{H}$ & $<1$ & 2.09 & 4.38 & 1.04 & 2.93 \\
$\mathrm{SAC}-4-2-\mathrm{SO}_{3} \mathrm{H}$ & $<1$ & 2.82 & 4.44 & 1.38 & 2.06 \\
$\mathrm{SAC}-4-3-\mathrm{SO}_{3} \mathrm{H}$ & $<1$ & 2.85 & 4.59 & 1.39 & 2.20 \\
\hline
\end{tabular}

${ }^{\mathrm{a}}$ Based on EDX of element $\mathrm{S}$

${ }^{b}$ Determined by titration using $\mathrm{NaOH}$

${ }^{\mathrm{c}}$ Determined by titration using $\mathrm{NaCl}$ exchange and subsequent titration

${ }^{\mathrm{d}}$ Obtained by subtracting the titration results of $\mathrm{NaCl}$ from the value of $\mathrm{NaHCO}_{3}$

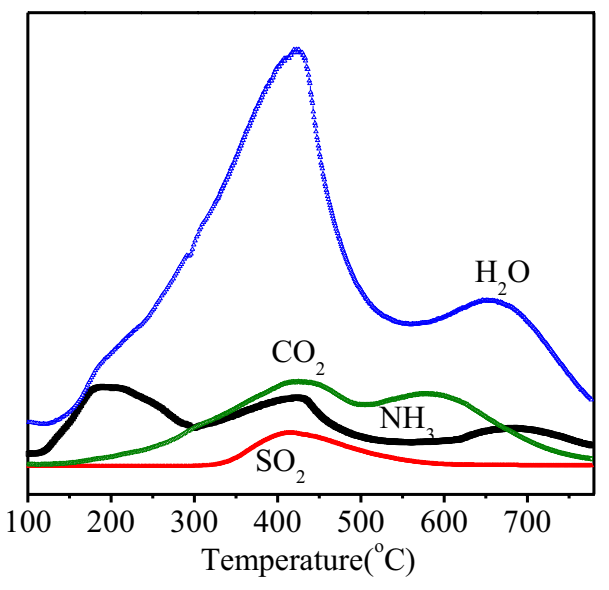

Fig. 4 The $\mathrm{NH}_{3}$-TPD results of $\mathrm{SO}_{3} \mathrm{H}$-functionalized solid acid catalyst $\mathrm{SAC}-4-2-\mathrm{SO}_{3} \mathrm{H}$

in $10^{\circ}$ to $30^{\circ}$, which could be attributed to (002) plane of amorphous carbon. However, the peak positions of the two samples are different. For sample $\mathrm{SAC}-4-0-\mathrm{SO}_{3} \mathrm{H}$, the peak is positioned at about $20^{\circ}$, while for $\mathrm{SAC}-4-2-\mathrm{SO}_{3} \mathrm{H}$, it is at $25^{\circ}$. This shows that although the material is amorphous, the addition of benzyl chloride is beneficial for the stacking of (002) plane and even more advantageous for the next step of sulfonation process, which could bring into more sulfonic groups. This may be another reason for the preparation of solid acid catalyst with high acid strength and acid amount.

TG analysis was used to study the thermal stability of the catalyst. Figure 6 shows TG curves of SAC-4-2- $\mathrm{SO}_{3} \mathrm{H}$ under the air flow condition. Before $100{ }^{\circ} \mathrm{C}$, the mass loss ratio was about $16 \%$, which was due to the desorption of water in the catalyst, indicating that the catalyst is highly hydrophilic, which is consistent with other reports [26]. The catalyst within the temperature range $100-260{ }^{\circ} \mathrm{C}$ has no apparent mass loss, less than $4 \%$, showing that the catalyst is very stable in this temperature range. With the rising of temperature, catalyst amounts also constantly decrease and burn out to $\mathrm{CO}_{2}, \mathrm{SO}_{2}$ and $\mathrm{H}_{2} \mathrm{O}$ at about $550{ }^{\circ} \mathrm{C}$. These data

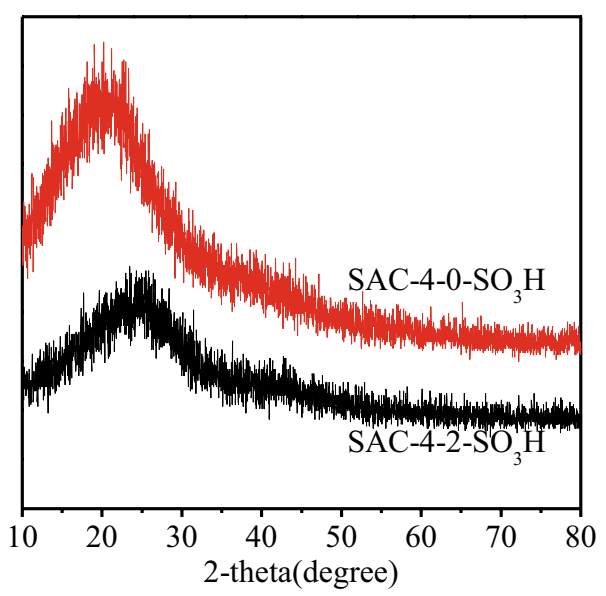

Fig. 5 The XRD patterns of $\mathrm{SO}_{3} \mathrm{H}$-functionalized solid acid catalyst SAC-4-0- $\mathrm{SO}_{3} \mathrm{H}$ and $\mathrm{SAC}-4-2-\mathrm{SO}_{3} \mathrm{H}$

show that compared with the general application temperature for sulfonic acid resin $\left(<150{ }^{\circ} \mathrm{C}\right)$, the current catalysts exhibit higher thermal stability [36].

\section{Catalytic performance}

\section{Succinic acid and ethanol esterification reaction}

Succinic acid, one of the top platform biological molecules, is an important raw material in the production of professional and bulk chemicals. Esterification reaction is one of the most useful reactions in the conversion of dicarboxylic acid to diester, and diester can be used as intermediates to produce polymer, fine chemicals, perfumes, plasticizer, solvents and so on. Table 2 compares the conversion of succinic acid and the selectivity toward diethyl succinate (DIES) with the catalyzing of various kinds of catalysts under the condition of $4 \mathrm{~h}$ reaction in the $80{ }^{\circ} \mathrm{C}$ oil bath. Because the esterification of succinic acid with ethanol is an autocatalytic reaction (Scheme 2), in order to more accurately show the catalytic performance of the above catalysts, we also studied 


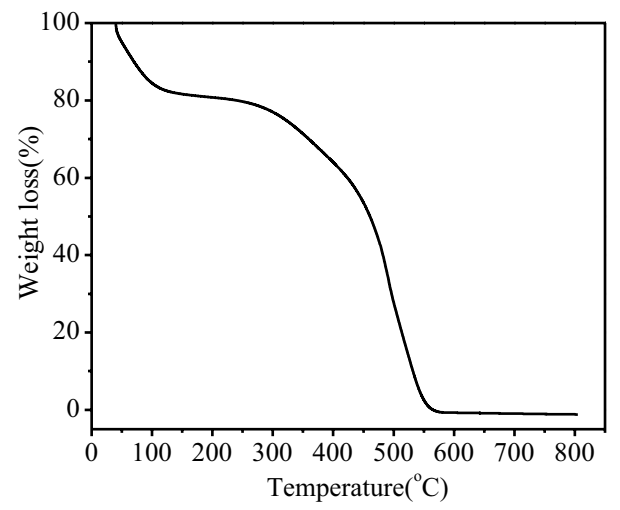

Fig. 6 The TG curve of $\mathrm{SO}_{3} \mathrm{H}$-functionalized solid acid catalyst SAC$4-2-\mathrm{SO}_{3} \mathrm{H}$ in a flow of air<smiles>O=C(O)CCC(=O)O</smiles>
succinic acid (SA)<smiles>O=C(O)CCC(=O)OCC[Te]</smiles>
ethyl succinate<smiles>CC(C)CCO</smiles><smiles>CCOC(=O)CCC(O)OCC</smiles>

diethyl succinate (DIES)
Scheme 2 Model reaction of the esterification of succinic acid with ethanol

Table 2 The surface properties of catalysts and their catalytic activities for the esterification ${ }^{\mathrm{a}}$

\begin{tabular}{|c|c|c|c|c|}
\hline Catalysts & $\mathrm{S}_{\mathrm{BET}}\left(\mathrm{m}^{2} / \mathrm{g}\right)$ & $\begin{array}{l}\text { Acid } \\
\text { density } \\
(\mathrm{mmol} / \mathrm{g})\end{array}$ & $\begin{array}{l}\text { Con- } \\
\text { version } \\
(\%)\end{array}$ & $\begin{array}{l}\text { Selectivity } \\
\text { to DIES }(\%)\end{array}$ \\
\hline $\mathrm{SAC}-4-2-\mathrm{SO}_{3} \mathrm{H}$ & $<1$ & $1.8^{\mathrm{b}}$ & 99 & 97 \\
\hline Amberlyst-15 & 53 & $4.0^{\mathrm{c}}$ & 99 & 68 \\
\hline $\mathrm{AC}-\mathrm{SO}_{3} \mathrm{H}$ & 506 & $0.0^{\mathrm{b}}$ & 98 & 47 \\
\hline $\mathrm{SAC}-4-0-\mathrm{SO}_{3} \mathrm{H}$ & 12 & $0.6^{\mathrm{b}}$ & 99 & 21 \\
\hline $\mathrm{H}-\beta$ & 590 & $1.0^{\mathrm{c}}$ & 99 & 21 \\
\hline No catalyst & - & - & 17 & 18 \\
\hline $\begin{array}{l}\text { Starbon- } \\
400-\mathrm{HSO}_{3}\left[{ }^{[11]]}\right.\end{array}$ & 386 & - & 90 & 80 \\
\hline \multicolumn{5}{|c|}{$\begin{array}{l}{ }^{a} \text { Reaction conditions: succinic } \\
\text { nol: } 80 \mathrm{mmol} \text {; catalyst: } 100 \mathrm{mg}, 80^{\circ} \mathrm{C}, 4 \mathrm{~h}\end{array}$} \\
\hline \multicolumn{5}{|c|}{${ }^{\mathrm{b}}$ Sulfonic group density from titration } \\
\hline${ }^{c}$ Data from the sup & & & & \\
\hline
\end{tabular}

the esterification without adding catalysts (other conditions were unchanged), and the results are listed in Table 2. As we can see, all of the catalyst for this reaction has high conversion of close to $100 \%$, but selectivity for DIES is very different. SAC-4-2- $\mathrm{SO}_{3} \mathrm{H}$ shows the highest selectivity of $97 \%$, and $\mathrm{AC}-\mathrm{SO}_{3} \mathrm{H}$ and $\mathrm{SAC}-4-0-\mathrm{SO}_{3} \mathrm{H}$ show a low selectivity. The results may be related to the sulfonic group content in the catalyst. Both SAC-4-0- $\mathrm{SO}_{3} \mathrm{H}$ and $\mathrm{AC}-\mathrm{SO}_{3} \mathrm{H}$ have relatively low sulfonic group content, while the SAC-4-2- $\mathrm{SO}_{3} \mathrm{H}$ has the highest. In other words, the amount of supreme sulfonic group is a key factor for the reactivity of sulfonated carbon material. One possible problem is that Amberlyst-15 contains the highest amount of sulfonic group, but the selectivity to DIES is still below that for SAC-4-2- $\mathrm{SO}_{3} \mathrm{H}$. Some reports suggest that this may be due to differences in surface chemical properties of catalysts [37]. Finally, H- $\beta$ molecular sieves showed the lowest DIES selectivity, which may be due to its lower acid strength. The reported catalytic activities of Starbon-400- $\mathrm{HSO}_{3}[14]$ are also listed in Table 2. SAC-4-2$\mathrm{SO}_{3} \mathrm{H}$ shows higher conversion and selectivity to DIES compared with Starbon-400- $\mathrm{HSO}_{3}$. The cycling stability of the SAC-4-2- $\mathrm{SO}_{3} \mathrm{H}$ catalysts for this reaction has been carefully studied. After the first cycle of the reaction, the centrifugal

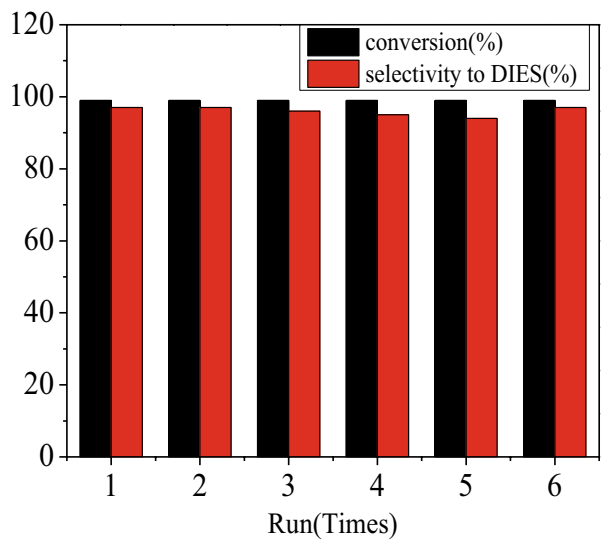

Fig. 7 The reusability of sample SAC-4-2- $\mathrm{SO}_{3} \mathrm{H}$ for the esterification of succinic acid

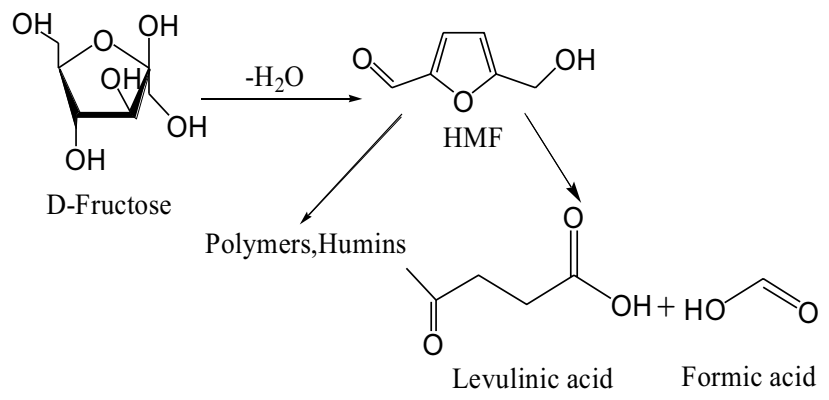

Scheme 3 Model reaction of the dehydration of fructose to HMF 
catalyst after washing with water and ethanol several times dried overnight at $90{ }^{\circ} \mathrm{C}$ in the oven. The dried catalyst was added into the fresh reactant with the same ratio, reacted for another five cycles. As shown in Fig. 7, after six cycles, the activity of the catalyst is not much changed. The succinic acid conversion is higher than $99 \%$ and the selectivity of DIES is also above $90 \%$. We can see that the catalyst has good stability.

\section{Dehydration of fructose to HMF}

5-HMF molecule contains an aldehyde and a hydroxymethyl group, and it can be used to synthesize various valuable chemicals and novel polymer materials through hydrogenation, dehydrogenation oxidation, esterification, halide, polymerization and hydrolysis [38]. Due to its high reactivity and multiple functional groups, it is a good raw material. Starting from HMF, a series of value-added products can be synthesized, such as levulinic acid, 2, 5-dimethylfuran, and 2, 5-furan dicarboxylic acid, which have been widely used for agricultural chemical fungicide, electrochemical corrosion inhibitor, dispersant, cosmetics and spices. Therefore, HMF is promising to become the new platform compounds based on biomass resources.

In conclusion, HMF has very high industrial value and more importantly can be prepared from natural biomass and thus to be a "green, renewable" platform molecule. Therefore, in recent years, the synthesis of HMF from biomass or sugar attracts great attentions (Scheme 3). As is known to all, good solvent DMSO is the realization of the reaction [37]. This is because in DMSO, fructose can be dehydrated easily because of its furan structure; at the same time, some side reactions can be inhibited, for example, the breaking down into levulinic acid or formic acid and aggregating into humin $[39,40]$. Because DMSO has a high boiling point, however, it leads to the difficulty separation in DMSO. Using low boiling point, solvents can solve the problem in separation and improve production for efficient solid acid

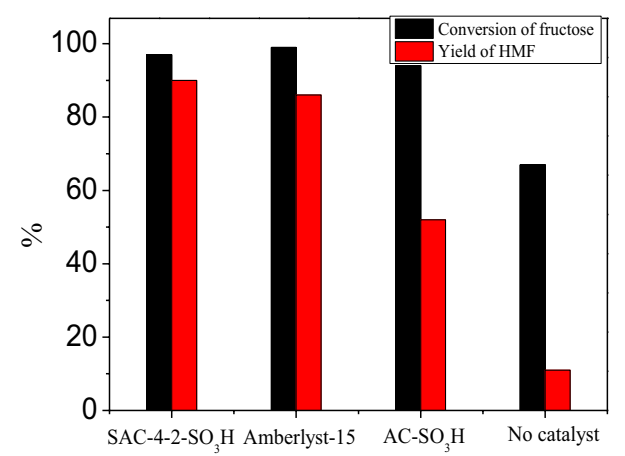

Fig. 8 The catalytic activities of different catalysts for the fructose dehydration
Table 3 The reusability of SAC4-2- $\mathrm{SO}_{3} \mathrm{H}$ for the dehydration of fructose to $\mathrm{HMF}$

\begin{tabular}{lll}
\hline Run & $\begin{array}{l}\text { Conversion } \\
\text { of fructose } \\
(\%)\end{array}$ & $\begin{array}{l}\text { Yield of } \\
\text { HMF (\%) }\end{array}$ \\
\hline 1 & 99 & 90 \\
2 & 99 & 91 \\
3 & 99 & 89 \\
4 & 99 & 90 \\
5 & 98 & 87 \\
\hline
\end{tabular}

catalyst. Here, acetone/DMSO mixture (volume ratio: 8/2) was used as solvents, and the catalytic properties of several kinds of catalyst were compared, as shown in Fig. 8. Without catalyst, the conversion of the fructose is about $70 \%$, but because of the side reactions, the selectivity of HMF is very low. The addition of catalyst can not only improve the conversion of fructose, but more importantly the selectivity. Among them, the SAC-4-2- $\mathrm{SO}_{3} \mathrm{H}$ showed the best catalytic activity and selectivity. When in $130^{\circ} \mathrm{C}$ after $1 \mathrm{~h}$ of reaction, the yield for $\mathrm{HMF}$ is as high as $90 \%$, even higher than that from Amberlyst-15. AC- $\mathrm{SO}_{3} \mathrm{H}$ shows the lowest catalytic activity, which may be due to its low quantity of sulfonic groups. SAC-4-2- $\mathrm{SO}_{3} \mathrm{H}$ also showed good cycling stability; after five cycles, the yield is still as high as $87 \%$, and catalytic activity has no significant loss, as listed in Table 3 .

Besides confined to the above reactions, the synthesis method has great potential in a lot of acid-catalyzed reactions. In addition, other monosaccharides and polysaccharides (fructose, sucrose, and even cellulose) can replace glucose to synthesis the catalyst. Sugar/benzyl chloride is prepared with cellulose/benzyl chloride-sulfonated carbon materials, which also showed high catalytic activity in the esterification reaction. To sum up, this is a simple and feasible method and can be used for the preparation of all kinds of efficient and controllable acid amount of solid acid catalyst.

\section{Conclusions}

High acid content and good thermal stability of sulfonated carbonaceous materials were prepared by the two-step synthesis method. Firstly, glucose and benzyl chloride were used to synthesize a kind of carbon black surface with phenyl at high temperature and then sulfonated with concentrated sulfuric acid and got the sulfonated carbon materials. Benzyl chloride has played a very important role in the process of material synthesis. Benzyl chloride on the benzene ring will have more sulfonic acid catalyst also more stable. And the amount of sulfonic group could be adjusted and controlled by adding the quantity of benzyl chloride. In a series of acid-catalyzed reaction, compared with the 
Amberlyst-15, the catalyst showed high catalytic activities, which suggests that it has great potential in green chemistry. Due to a variety of biomass that can be used as the starting materials, the current method is not limited to glucose, and as a result, a useful reference provides the regulation of the synthesis of carbon-based solid acid catalysts.

Acknowledgements The authors express their sincere gratefulness for the financial support from the National Natural Science Foundation of China (21406062) and Fundamental Research Funds for the Central Universities (22A201514007).

Open Access This article is licensed under a Creative Commons Attribution 4.0 International License, which permits use, sharing, adaptation, distribution and reproduction in any medium or format, as long as you give appropriate credit to the original author(s) and the source, provide a link to the Creative Commons licence, and indicate if changes were made. The images or other third party material in this article are included in the article's Creative Commons licence, unless indicated otherwise in a credit line to the material. If material is not included in the article's Creative Commons licence and your intended use is not permitted by statutory regulation or exceeds the permitted use, you will need to obtain permission directly from the copyright holder. To view a copy of this licence, visit http://creativecommons.org/licenses/by/4.0/.

\section{References}

1. M. Yabushita, H. Kobayashi, A. Fukuoka, Appl. Catal. B Environ. 145, 1 (2014)

2. H.M. Morgan Jr., Q. Bu, J. Liang, Y. Liu, H. Mao, A. Shi, H. Lei, R. Ruan, Bioresour. Technol. 230, 112 (2017)

3. H. Chen, J. Liu, X. Chang, D. Chen, Y. Xue, P. Liu, H. Lin, S. Han, Fuel Process. Technol. 160, 196 (2017)

4. M.L. Zhang, K.M. Su, H.M. Song, Catal. Commun. 69, 76 (2015)

5. H.B. Zhao, J.E. Holladay, H. Brown, Science 316, 1597 (2007)

6. C. Carlini, P. Patrono, A.M.R. Galleti, Appl. Catal. A Gen. 275, $111(2004)$

7. A. Maleki, Z. Hajizadeh, P. Salehi, Sci. Rep. 9, 5552 (2019)

8. A. Maleki, M. Aghaei, R. Paydar, J. Iran. Chem. Soc. 14, 485 (2017)

9. A. Maleki, A.A. Jafari, S. Yousefi, J. Iran. Chem. Soc. 14, 1801 (2017)

10. A. Maleki, V. Eskandarpour, J. Iran. Chem. Soc. 16, 1459 (2019)

11. D. Sarma, B. Majumdar, T.K. Sarma, Green Chem. 21, 6717 (2019)
12. L. Peng, A. Philippaerts, X. Ke, J.V. Noyen, F.D. Clippel, G.V. Tendeloo, P.A. Jacobs, B.F. Sels, Catal. Today 150, 140 (2010)

13. L. Geng, Y. Wang, G. Yu, Y. Zhu, Catal. Commun. 13, 26 (2011)

14. J.H. Clark, V. Budarin, T. Dugmore, R. Luque, D.J. Macquarrie, V. Strelko, Catal. Commun. 9, 1709 (2008)

15. M. Toda, A. Takagaki, M. Okamura, J.N. Kondo, S. Hayashi, K. Domen, M. Hara, Nature 438, 178 (2005)

16. J.J. Wang, W.J. Xu, J.W. Ren, X.H. Liu, G.Z. Lu, Y.Q. Wang, Green Chem. 13, 2678 (2011)

17. J.J. Wang, J.W. Ren, X. Liu, G. Lu, Y. Wang, AIChE J. 59, 2558 (2013)

18. L. Geng, G. Yu, Y. Wang, Y. Zhu, Appl. Catal. A Gel. 427, 137 (2012)

19. B.H. Zhang, J.W. Ren, X.H. Liu, Y.L. Guo, Y. Guo, G.Z. Lu, Y.Q. Wang, Catal. Commun. 11, 629 (2010)

20. R. Jia, J.W. Ren, X.H. Liu, G.Z. Lu, Y.Q. Wang, J. Mater. Chem. A 2, 11195 (2014)

21. F. Shen, T.M. Guo, C.X. Bai, M. Qiu, X.H. Qi, Fuel Process. Technol. 169, 244 (2018)

22. J. Pang, A. Wang, M.Y. Zheng, T. Zhang, Chem. Commun. 46, $6935(2010)$

23. V. Budarin, J.H. Clark, R. Luque, Chem. Commun. 6, 634 (2007)

24. W.Y. Lou, M.H. Zong, Z.Q. Duan, Bioresour. Technol. 99, 8752 (2008)

25. P. Gupta, S. Paul, Green Chem. 13, 2365 (2011)

26. M. Hara, T. Yoshida, A. Takagaki, Angew. Chem. Int. Ed. 43, $2955(2004)$

27. M. Okamura, A. Takagaki, M. Toda, Chem. Mater. 18, 3039 (2006)

28. X.M. Sun, Y.D. Li, Angew. Chem. Int. Ed. 43, 597 (2004)

29. B. Hu, S.H. Yu, K. Wang, Dalton Trans. 40, 5414 (2008)

30. R. Demir-Cakan, P. Makowski, M. Antonietti, Catal. Today 150, 115 (2010)

31. R. Demir-Cakan, N. Baccile, M. Antonietti, Chem. Mater. 21, 484 (2009)

32. A. Contescu, C. Contescu, K. Putyera, Carbon 35, 83 (1997)

33. C. Falco, F.P. Caballero, F. Babonneau, Langmuir 27, 14460 (2011)

34. D.S. Bag, V.P. Kumar, S. Maiti, J. Appl. Polym. Sci. 71, 1041 (1999)

35. X.Z. Liang, M.F. Zeng, C.Z. Qi, Carbon 48, 1844 (2010)

36. B.F.M. Kuster, Starch 42, 314 (1990)

37. S. Suganuma, K. Nakajima, M. Kitano, J. Am. Chem. Soc. 130, 12787 (2008)

38. N.A.S. Ramli, N.A.S. Amin, J. Mol. Catal. A Chem. 407, 113 (2015)

39. M. Bicker, D. Kaiser, L. Ott, Supercrit. Fluids 36, 118 (2005)

40. F.W. Lichtenthaler, Carbohydr. Res. 313, 69 (1998) 